\title{
Healthy retirement begins at school: educational differences in the health outcomes of early transitions into retirement
}

\author{
Kasim Allel ${ }^{1,2}$, Ana Sofía León ${ }^{3}$, Ursula M. Staudinger ${ }^{4}$ and Esteban Calvo ${ }^{1,5 *}$ \\ ${ }^{1}$ Society and Health Research Center and Laboratory on Aging and Social Epidemiology, School of Public \\ Health, Universidad Mayor, Santiago, Chile, ${ }^{2}$ Millennium Nucleus for the Study of the Life Course and \\ Vulnerability (MLIV), Chile, ${ }^{3}$ Department of Economics, School of Business and Economics, Universidad \\ Diego Portales, Santiago, Chile, ${ }^{4}$ Department of Sociomedical Sciences and Robert N. Butler Columbia \\ Aging Center, Mailman School of Public Health, Columbia University, New York, USA and ${ }^{5}$ Department \\ of Epidemiology and Robert N. Butler Columbia Aging Center, Mailman School of Public Health, \\ Columbia University, New York, USA \\ ${ }^{*}$ Corresponding author. Email: esteban.calvo@columbia.edu
}

(Accepted 18 June 2019; first published online 5 August 2019)

\begin{abstract}
The literature on socio-economic variations in the association between retirement timing and health is inconclusive and largely limited to the moderating role of occupation. By selecting the sample case of Mexico where a sizeable number of older adults have no or very little formal education, this study allows the moderating role of education to be tested properly. Drawing on panel data for 2,430 individuals age 50 and over from the Mexican Health and Aging Study (MHAS) and combining propensity score matching models with fixed-effects regressions, this article investigates differences in the health effects of retirement timing between older adults with varying years of education. Subjective health is measured using a self-reported assessment of respondents' overall health and physical health as a reverse count of doctor-diagnosed chronic diseases. The results indicate that early transitions into retirement are associated with worse health outcomes, but education fully compensates for the detrimental association with subjective and physical health, while adjusting for baseline health, demographics and socio-economic characteristics. In conclusion, formal education during childhood and adolescence is associated with a long-term protective effect on health. It attenuates negative health consequences of early retirement transitions. Policies and programmes promoting healthy and active ageing would benefit from considering the influence of formal education in shaping older adults' health after the transition into retirement.
\end{abstract}

Keywords: education; employment; work; retirement; self-reported health; chronic disease; developing countries; lifecourse

(c) Cambridge University Press 2019. This is an Open Access article, distributed under the terms of the Creative Commons Attribution licence (http://creativecommons.org/licenses/by/4.0/), which permits unrestricted re-use, distribution, and reproduction in any medium, provided the original work is properly cited. 


\section{Introduction}

Population ageing is frequently perceived as a cause of concern, but various responses are available to address it (Staudinger and Kocka, 2010; Bloom et al., 2015; Rowe, 2015). For example, individuals can respond to their longer lives by making greater investments in their human capital through training and prolonged workforce participation, while policy responses include investments in education and promotion of labour-force participation at older ages. A top priority should be to find behavioural and policy responses that simultaneously promote positive economic and health outcomes (Staudinger et al., 2016).

Increasing education is perhaps one of the most promising interventions to achieve a combination of productive and healthy ageing (Morrow-Howell et al., 2001; Lutz et al., 2014). More-educated individuals are better prepared to make use of new technologies and to adjust to changing environments, such as a new job or life after retirement (Jamieson, 2007; Bonsang and Van Soest, 2014; Rehkopf et al., 2017; Narushima et al., 2018). Formal education is defined in this article as total years of formal education completed starting from elementary school.

The non-pecuniary returns to education are explained in the economic literature through the 'allocative efficiency model', which refers to situations in which more-educated individuals choose a more efficient mix of inputs (e.g. time and money) to maximise health (or any given outcome) relative to less-educated individuals facing similar circumstances (Grossman, 2006; Oreopoulos and Salvanes, 2011). Numerous studies in high-income countries have used exogenous variation in accessibility to formal education as a natural experiment, finding that good health is a key non-pecuniary benefit from additional schooling (Lleras-Muney, 2005; Currie and Moretti, 2007; Cutler and Lleras-Muney, 2008). A smaller set of studies has identified the mechanisms underlying the link between formal education and health outcomes (Ross and Mirowsky, 1999; Cutler and Lleras-Muney, 2010; Vogl, 2014). This literature, however, is not specific to the health effects of retirement timing. The present article adds to the literature on non-pecuniary returns on formal education by highlighting that further support for the allocative efficiency model may lie in testing how years of education affect the association between retirement timing and health status after retirement.

In particular, the present study examined how formal education moderates (or differentiates) the association between retirement timing and health in a country that hosts a full (and not a restricted) range of educational exposures; in this case, Mexico. By focusing on Mexico, we remedy data constraints in the extant literature focusing on high-income countries which are characterised by a restricted range of years of education. Extant literature is not only limited to high-income countries, but also fragmented, with one group of studies focusing on the relationship between education and health (Mäki et al., 2014) and another group of studies concentrating on the health effects of retirement (Fisher et al., 2016); the latter often ignoring the socio-economic differences in the association between retirement and health or only considering the moderating role of occupation, not education (Iparraguirre, 2014). As literature directly testing the moderation effect of education on the association between retirement timing and health is virtually missing, we reviewed literature on the lifecourse health effects of education, health effects of 
retirement timing and specific studies on occupational variations in the health effects of retirement timing to inform the hypotheses of this study.

In the following sections, we review these literatures, formulate research hypotheses and justify the selection of Mexico as our case study. Next, we discuss our methodological approach. After presenting our results, we discuss policy and practical implications for 'societies of longer lives' (Staudinger, 2015). Most notably, we emphasise how policies concerned with healthy and positive ageing are inextricably linked to salient antecedents such as the timing of retirement, as well as to earlier antecedents such as formal education.

\section{Literature review}

\section{Lifecourse health effects of education}

Numerous studies document that education is strongly associated with health over the lifecourse (Luo and Waite, 2005; Jamieson, 2007; Cutler and Lleras-Muney, 2008, 2010; Mäki et al., 2014). Education is strongly associated with psychological, social and financial resources that are helpful to deal with health shocks (Kawachi et al., 2010). Consistently, numerous studies have documented that more formal education has preventive effects as it lowers health risk, improves cognition and prolongs life expectancy, regardless of being in the labour force or not (Luo and Waite, 2005; Lutz and Samir, 2011; Majer et al., 2011; Mäki et al., 2014; Cutler et al., 2015). Not only formal education, but also lifelong learning through volunteering and training seem to support mental health and cognitive development among adults and older adults (Ball et al., 2002; Baltes et al., 2006). However, there is also evidence that the protective health effects of education may weaken with age (Van Dijk et al., 2008).

\section{Health effects of retirement timing}

Regarding the health effects of retirement timing, a large fraction of this literature suggests transitions that happen too early to have detrimental effects on health, which are partly explained by losses in financial, social and psychological resources (Siegrist et al., 2007; Dhaval et al., 2008; Zins et al., 2011; Behncke, 2012; Kuhntopf and Tivig, 2012; Van der Heide et al., 2013; Van der Noordt et al., 2014; Fisher et al., 2016). Although it is clear that this relationship goes both ways, studies using panel data and an instrumental variable approach suggest that retirement timing causes changes in physical and mental health (Bonsang and Klein, 2012; Bonsang et al., 2012; Calvo et al., 2013; Kajitani et al., 2016; Mazzonna and Peracchi, 2016). However, the benefits of working beyond normative ages are not clear (Calvo et al., 2013). Usually, education is controlled in such analyses, and is not conceptualised as possibly moderating the health effect of retirement timing (Fisher et al., 2016).

\section{Socio-economic variation in the association between retirement timing and health}

The lack of empirical evidence about the moderating effect of education on the health outcomes of retirement timing may partly be explained by the fact that 
studies are largely restricted to high-income countries, where 'no' or 'little education' is such a rare event that the moderating role of education cannot be properly tested. Thus, studies that inform the association between retirement timing and health typically control for education, but they do not investigate education as a potential moderator of the health effects of retirement timing and often focus just on retirement status instead of the timing of retirement (Fisher et al., 2016).

For example, a recent study by Hessel (2016) in 12 European countries analysed the effects of retirement on self-rated health, limitations in activities of daily living and the presence of chronic conditions, combining an instrumental variable approach with models stratified by gender and educational level. The role of education as a moderator, however, was inconclusive. On the one hand, retirement was associated with significantly worse self-reported health among highly as compared to low-educated women (but not men), suggesting that less education had a protective effect for women. On the other hand, education neither modified the significant association between retirement and increases in functional limitations (for both genders) nor did it modify the lack of association between retirement and the presence of chronic conditions. In another study by Majer et al. (2011), education was not directly modelled as a moderator of the health effects of retirement timing either, but the results suggested that individuals with higher levels of education lived in better health before retirement and also lived longer afterwards compared to those with lower educational levels. These observed socio-economic inequalities in health favour the higher educated, but it is unclear whether or not they may moderate the health consequences of retirement timing.

Studies examining socio-economic variations in the health effects of retirement have paid less attention to education and instead focused on the type and prestige of the occupation from which individuals retire as a potential moderator of health effects of retirement (Iparraguirre, 2014). The study samples are similarly restricted to high-income countries and the findings are also inconclusive. A fairly large group of studies provides evidence that individuals who retire from jobs with lower prestige and worse working conditions are in worse health after retirement than those who retire from jobs with higher prestige and better working conditions (Mein et al., 2003; Nooyens et al., 2005; Neuman, 2006; Chung et al., 2009). In the United States of America (USA), a study using an instrumental variable approach concluded that retirement had no strong association with health, though may slightly increase the likelihood of depression for men retiring from a low-skill bluecollar occupation (Neuman, 2006). Another study in the USA documented that retirement from a physically demanding job (which typically indicates lower SES) was associated with a decrease in physical activity, while retiring from a sedentary job was associated with an increase in physical activity, and that these associations were further exacerbated by wealth, which is another indicator of socio-economic status (SES) (Chung et al., 2009). Similarly, a study in the Netherlands found that retirement was significantly associated with increases in weight and waist circumference among individuals retiring from physically active jobs, but not among those retiring from sedentary jobs (Nooyens et al., 2005). Among British civil servants, retirement at age 60 was not significantly associated with physical health, and if anything was weakly associated with mental health improvements among higher-grade occupations (Mein et al., 2003). Finally, retiring 
from jobs involving more complex tasks, which are typically available to individuals with more education, seems to be associated with better cognitive outcomes in the USA (Fisher et al., 2014), Japan (Kajitani et al., 2016) and many European countries (Mazzonna and Peracchi, 2016).

A smaller group of studies that differentiate the health effects of retirement by occupation reached mixed results. Relative to British civil servants in low occupational grades, those in high grades experienced better mental health but poorer physical health trajectories after retirement (Chandola et al., 2007). In France, harmful health behaviours such as heavy alcohol consumption increased around retirement and decreased in the years thereafter, but these changes varied in complex ways by type of occupation across males and females (Zins et al., 2011). Males in manual low-SES occupations remained more stable in heavy alcohol consumption before and after retirement and females in managerial high-SES and clerical low-SES occupations (not in intermediate-SES occupations) did not experience a decrease after retirement.

Yet, another study in the USA using an instrumental variable approach found no clear-cut association between retirement and health or cognition for white-collar workers and, if anything, a beneficial effect of retirement for blue-collar workers (Coe et al., 2012). To our knowledge, this is the only study that suggests that higher occupational status may make the health effects of retirement worse.

In sum, whether education differentiates the association between retirement timing and health remains unclear (Scharn et al., 2018). The lack of empirical evidence on the moderating role of education can be partly attributed to the fact that studies are largely restricted to high-income countries, where few older adults have little or no education. Studies considering the impact of type and prestige of occupation on the association between retirement and health are also restricted to high-income countries (Iparraguirre, 2014). Higher SES, as measured by the type and prestige of occupation, seems to be weakly associated, if anything, with better health outcomes of retiring (Mein et al., 2003; Nooyens et al., 2005; Neuman, 2006; Chung et al., 2009), but the results are inconclusive (Chandola et al., 2007; Zins et al., 2011; Coe et al., 2012). These weak and inconclusive results are consistent with the fact that socio-economic differences in health based on occupation seem to decrease after retirement more than those based on education (Marmot and Shipley, 1996).

\section{Health outcome specificity}

Previous literature calls for studies to focus on specific health outcomes, as the association between retirement timing and health, as well as the pathways connecting them, are outcome-specific (Iparraguirre, 2014; Fisher et al., 2016). Relative to physical health outcomes, previous evidence suggests that subjective health outcomes are fairly sensitive to SES-related exposures, including educational level (Maas et al., 2006; Hessel, 2016), cognitive inequalities (Borgonovi and Pokropek, 2016), financial resources and material disadvantage (Franks et al., 2003), as well as social connectedness and resilience (Stewart et al., 2019). Physical health outcomes are also sensitive to these and other SES-related exposures, but they 'get under the skin' albeit through more complex and longer 
pathways (Ferraro and Shippee, 2009; Miller et al., 2009; Hertzman and Boyce, 2010; Phelan et al., 2010; Matthews and Gallo, 2011). Therefore, considering specific outcomes and potential differences between them is important to a more comprehensive and nuanced understanding of the socio-economic variation in the association between retirement timing and health.

\section{Research hypotheses}

Overall, the literature reviewed suggests that it is plausible to hypothesise that more education protects individuals and buffers the negative health consequences of early transitions into retirement over and above the effect of the type of occupation. We further hypothesised that the moderating effect of education is stronger for subjective than physical health consequences of early transitions into retirement.

\section{Mexico as a case study}

We suggest that part of the dearth of studies and inconsistencies in the extant literature may have to do with the limited educational variance observed in highincome countries and consequently selected a country that displayed a broader range of educational levels from none to college degrees and beyond. We assumed that having a wider range of educational levels available would represent a fairer test of the possible compensatory effect of education, that is, more years of formal education would buffer the negative health consequences of early transitions into retirement. Specifically, we selected Mexico as a case study to explore the role of education in explaining differences in the subjective and physical health effects of retirement timing.

Compared to most high-income countries, Mexico is ageing at a faster rate while its older population has lower levels of schooling and health (Palloni et al., 2002; Wong and Palloni, 2009; United Nations, 2015). Thus, Mexico allows us to include a sizeable group of individuals with low and very low levels of formal education in the analysis (in our sample, $24.03 \%$ of older adults working in the formal economy have no education). This percentage cannot be found in most high-income countries, where virtually all older adults have completed high school and a substantial fraction had access to tertiary education. In this challenging scenario, Mexicans typically retire in their early sixties, with only half of them having contributed to social security and many experiencing poor health outcomes (Aguila et al., 2011; Murill and Venegas, 2011).

\section{Methods}

\section{Data collection}

We used nationally representative panel data of older adults age 50 and over and their spouses from the Mexican Health and Aging Study (MHAS). With support from the National Institute of Health, MHAS followed up 21,421 individuals in 2001, 2003 and 2013 (Instituto Nacional de Estadística y Geografía, 2012; Wong et al., 2015). We restricted our sample to 2,430 individuals aged 50 and over surveyed in 2001 
(baseline year of the study), participating in the formal labour force and social security system at baseline, and neither retired nor dead during the observation period (see Figure 1). Selectivity effects by socio-demographics and health variables were overall fairly small (see Figure A1 in the online supplementary material). If anything, it is worth noting that relative to excluded individuals, those in the analytic sample have higher SES as measured by education but lower SES as measured by occupation, and are more likely to have employed spouses.

\section{Measurements of health outcomes}

We used subjective and physical health as main dependent variables. Subjective health was measured using a five-point Likert scale ranging from 'poor' to 'excellent'. Our physical health index is a reverse count of the following chronic conditions: high blood pressure or hypertension, diabetes or high blood sugar, chronic lung disease except asthma, cancer or malignant tumour except skin cancer, heart problems, strokes, and arthritis or rheumatism. This variable ranges from zero to seven, with a higher value indicating better health or absence of chronic diseases.

\section{Measurements of formal education and retirement timing}

To measure formal education, we used years of education completed. To measure retirement timing we used retirement status, current age, current age squared, and interaction terms between retirement status and each of the age variables. Retirement status was computed as a dichotomy indicating that the respondent was receiving retirement benefits or not working because of retirement. Current age was measured in years, centred at 60 and divided by 10 for analytical purposes.

\section{Covariates}

We included a wide range of socio-economic, functioning and lifestyle measures as time-varying covariates in the fixed-effects models. Income was calculated as the sum of annual earnings from business, real estate, capital goods, salary, transfers and pensions, measured in $\$ 1,000$ units of 2010 Consumer Price Index-adjusted US dollars, and logarithmically transformed to improve normality and linearity. Spousal employment status was measured with dummy variables indicating a non-employed spouse, an employed spouse and no spouse as the reference category. Being out of the labour force status was measured as a dichotomy indicating spells out of the labour force for reasons other than retirement. Functional limitations were measured on a $0-5$ scale by counting any difficulties in performing the following activities of daily living: dressing, going to the bathroom, eating, going to bed and walking several blocks. Psychological health was based on a reverse count of eight depressive symptoms from a reduced version of the Center for Epidemiological Studies Depression Scale (CES-D), including positive and negative affects, as well as somatic symptoms. Smoking status was measured as a categorical variable indicating individuals that currently smoke, ever smoked and never smoked as the reference category. Alcohol behaviour was measured as a categorical variable too, using abstainers as the reference category and indicating three types of 


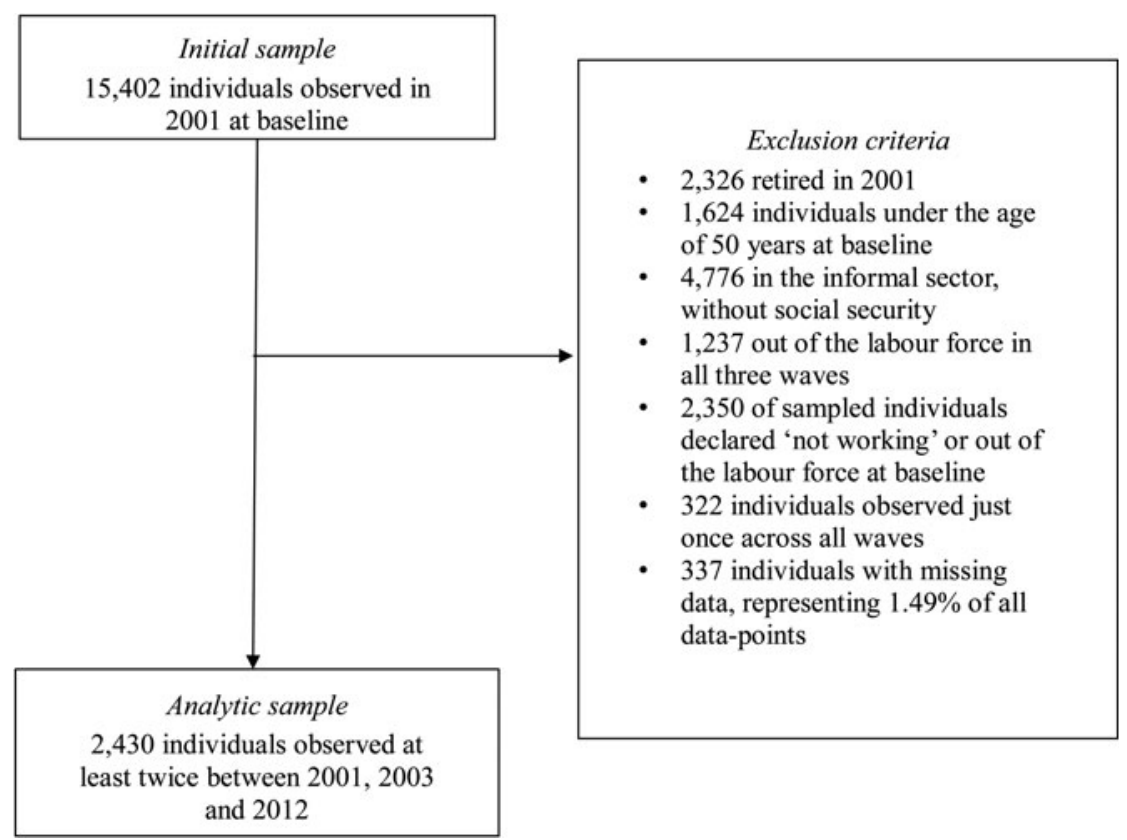

Figure 1. Sample construction.

drinkers: light ( $<1$ drink per day), moderate (1-2.5 drinks per day) and heavy ( $>2.5$ drinks per day). The inclusion of a wide range of covariates was intended to minimise selectivity and omit variable biases.

In the propensity score estimation we included all the covariates mentioned above, combined with gender, ethnicity and type of occupation, all measured as time-invariant covariates at baseline. Gender was measured as a dichotomy indicating women. Ethnicity was also a dichotomy indicating whether or not the respondent speaks an indigenous dialect. Life-time occupation type was measured at baseline for the main job and classified in three groups: blue-collar (agriculture/forestry/fishing, mechanics/repairing, construction industry, extractor, army operators and members of the army), pink-collar (sales occupations/office workers/support and administrative services such as cleaning, protection, food preparation, health services and personal services) and white-collar occupations (professional occupations and directors) as the reference category. Because the goal of the propensity score estimation is an accurate prediction and not a parsimonious explanation, we used all variables regardless of statistical significance.

\section{Statistical analyses}

In order to analyse how having more or less years of formal education moderated the later-life health outcomes of early transitions into retirement, we estimated separated longitudinal linear regression models for subjective and physical health, employing propensity score matching to account for treatment selectivity. For each 
individual $i$ at time $t$, the health effects of retirement timing were estimated through the model formalised in Equation (1):

$$
\begin{gathered}
Y_{i t}=\alpha_{0}+\beta_{1} \times \text { Retirement }_{i t}+\beta_{2} \times \text { Age }_{i t}+\beta_{3} \times \text { Retirement }_{i t} \times \text { Age }_{i t}+\beta_{4} \times \\
\text { Age }_{i t}^{2}+\beta_{5} \times \text { Retirement }_{i t} \times \text { Age }_{i t}^{2}+\beta_{6} \times \text { Retirement }_{i t} \times \text { Education }_{i t}+ \\
\beta_{7} \times \text { Retirement }_{i t} \times \text { Education }_{i t} \times \text { Age }_{i t}+\beta_{8} \times \text { Retirement }_{i t} \times \text { Education }_{i t} \times \\
\text { Age }_{i t}^{2}+\beta_{9} \times \text { Education }_{i t} \times \text { Age }_{i t}+\beta_{10} \times \text { Education }_{i t} \times \text { Age }_{i t}^{2}+X_{i}+u_{i}+e_{i t}
\end{gathered}
$$

where $Y_{i t}$ is the predicted health of respondent $i$ at time $t, \alpha_{0}$ is the constant term or average health, $\beta$ represents the estimated effects for the corresponding variable, Retirement $_{i t}$ is a variable indicating the status of being retired, Age ${ }_{i t}$ is measured in years centred to the mean, Education ${ }_{i t}$ indicates years of education of the respondent, $X_{i}$ is a vector containing all time-invariant covariates, and $e_{i t}$ and $u_{i}$ represent time-varying and time-invariant error terms, respectively. The three-way interaction terms between retirement status, years of education, and both linear and quadratic age $\left(\beta_{7} \times\right.$ Retirement $_{i t} \times$ Education $_{i t} \times$ Age $_{i t}$ and $\beta_{8} \times$ Retirement $_{i t} \times$ Education $_{i t} \times \mathrm{Age}_{i t}^{2}$ ) are needed to test whether formal education buffers the detrimental health outcomes of retirement timing. Performing these estimations separately for subjective and physical health outcomes, and (also separately) plotting predicted health values for individuals that retired and remained in the labour force and their differences in predicted health values by age, allowed exploration of whether or not the moderating effect of education is stronger for subjective than physical health consequences of early transitions into retirement.

Because health crises are one of the possible reasons forcing people out of their jobs at earlier ages, the health effects of retirement timing can be overestimated unless we addressed the endogeneity of retirement timing to health. We addressed this issue by estimating fixed-effects regression models using propensity score weights, without changing the weights across waves (Imai and Kim, 2019). Propensity score techniques weight each individual from the analytic sample using a score corresponding to the estimated probability of receiving the treatment (in this case retiring over the observed period), conditional on individuals' characteristics at baseline, such that the weighted distribution of the observable characteristics is the same for the treated and untreated groups (Rosenbaum and Rubin, 1983). By weighting individuals using their conditional probability of retirement given a comprehensive set of characteristics observed at baseline year 2001, we adjusted our estimation of the average treatment effect on the treated for individual differences at baseline that could be related to retirement.

Specifically, for each individual we estimated the conditional probability of being retired during the observed period (i.e. receiving treatment) through the logistic model formalised in Equation (2):

$$
\ln \left[\frac{e\left(z_{i}\right)}{1-e\left(z_{i}\right)}\right]=\ln \left[\frac{\operatorname{Pr}\left(\text { Retired }_{i}=1 \mid Z_{i}\right)}{1-\operatorname{Pr}\left(\operatorname{Retired}_{i}=1 \mid Z_{i}\right)}\right]=\alpha_{0}+\beta_{k} Z_{i}
$$


where $e\left(z_{i}\right)$ is the propensity score based on the probability of being retired (receiving treatment), conditional on a series of individual characteristics at baseline included in vector $Z_{i}$. $Z_{i}$ includes health measures, and functioning, lifestyle, demographic and socio-economic characteristics measured at baseline. For all continuous variables we also included squared terms to obtain the most accurate propensity score in case of non-linear effects on the probability of being retired. The resulting propensity scores have similar distributions for treated and untreated individuals, as indicated by the kernel distribution of the propensity score estimation in Figure 2, suggesting that propensity score estimates will yield appropriate and fully sampleweighted results (Dehejia and Wahba, 2002).

After obtaining the propensity score (PS), we calculated weights for each individual using Equations (3) and (4):

$$
\begin{gathered}
\text { Treated case weight }: \frac{1}{\mathrm{PS}} \\
\text { Untreated case weight }: \frac{1}{1-\mathrm{PS}}
\end{gathered}
$$

For each of our outcomes of interest, subjective and physical health, we estimated fixed-effects versions of the model shown in Equation (1) using Weighted Least Squares (WLS; Rubin, 1997; Hirano and Imbens, 2001; Freedman and Berk, 2008) and adjusting standard errors for clustering within the same household (Kaufman and Rousseeuw, 2009). We present conservative fixed-effects model for physical and subjective health (Hausman test $p<0.001$ ). Because physical health is a count variable and is somewhat left-skewed (see Figure A2 in the online supplementary material), we compared our WLS results to those obtained using weighted Poisson regression, finding similar results for the coefficients of interest (see Table A2 in the online supplementary material). We also estimated random-effects models adding time-invariant covariates; these models reached similar results for the coefficients of interest, but smaller confidence intervals for the figures given their more parsimonious nature (results available from the authors upon request).

\section{Results}

Table 1 shows the descriptive statistics for the first wave, last wave and average across all three 2001, 2003 and 2012 waves. These descriptive statistics suggest that - as to be expected for this age range - both health outcomes significantly decrease between the first and last waves. Also, they show that, on average, respondents have slightly more than six years of education, and that 51.03 per cent retired over the observed period of 11 years. Covariates behave as expected, but it is worth noting the increasingly high proportions of non-employed spouses and blue-collar workers, as well as the high number of functional limitations.

Results from the propensity score models are presented in Table A1 in the online supplementary material. They suggest that higher subjective health, education and income, as well as ever or current smoking status, significantly increased the probability of being retired, while being single and higher age showed the opposite 


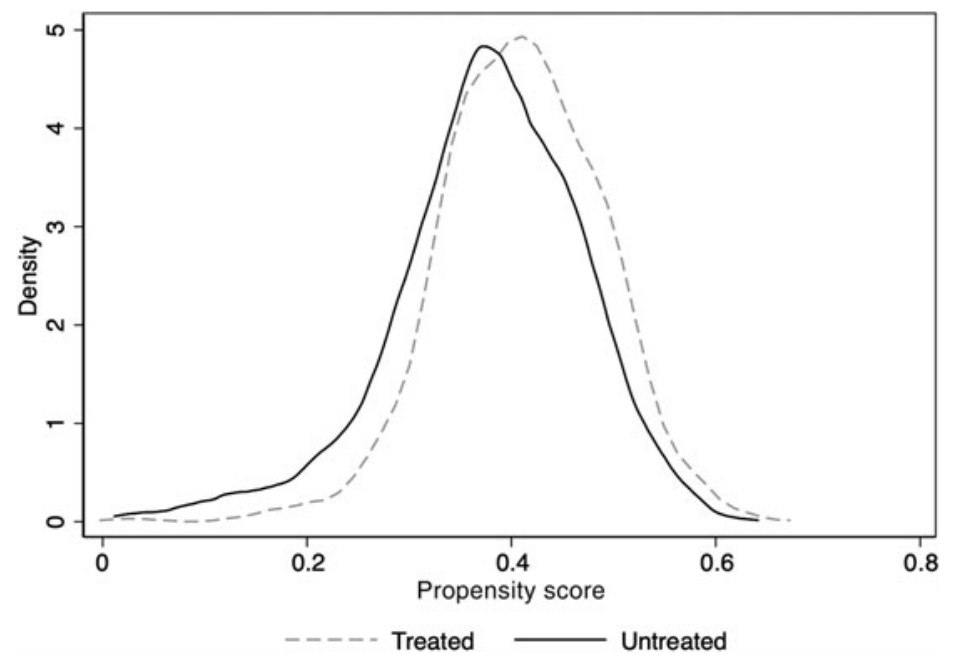

Figure 2. Kernel distribution of the propensity score estimation.

Notes: Propensity score estimation includes the following independent variables: subjective health and its squared term, physical health and its squared term, functional health limitations and its squared term, years of formal education, current age in years centred with the corresponding squared terms, income logged, spouse working status, having no spouse, sex, indigenous ethnicity, and blue-collar and clerical occupations.

association. Overall, the predicted probability of retiring ranged from 0.01 to 0.60 $($ mean $=0.38$, standard deviation $=0.06)$.

Table 2 summarises the core results of this study based on fixed-effects regression models that incorporate the predicted probabilities of retirement as weights. The constant suggests that individuals who are working, have an employed spouse, never smoked or drank, have no formal education, and have mean values in all continuous variables, have an average subjective health of 1.99 (on a scale ranging from 0 to 4 ) and an average physical health of 5.99 (on a scale ranging from 0 to 7 ). The main effects of retirement timing suggest that better health outcomes are associated with not being retired, and that younger age is associated with better physical health.

However, there are significant interactions between the status of being retired, current age and education (joint tests of significance $p<0.001$ ). The two-way interaction between retirement and age suggests that earlier retirement is associated with worse health outcomes. However, the three-way interactions including education suggest that the associations of earlier retirement with worse health outcomes are stronger for individuals with lower levels of education. Notably, this finding is above and beyond the differences in reasons for early retirement.

Figures 3 and 4 illustrate these results by plotting predicted health values by age for individuals that retired and those that remained in the labour force (top panels) and the difference between the two in predicted health values (bottom panels). The difference in predicted values between those retired and those still in the labour force can be interpreted as the health effect of retiring versus remaining in the labour force at a specific age. Dashed lines show the 95 per cent confidence intervals for these estimations. These results are presented for individuals with and without formal education (right and left panels, respectively). 
Table 1. Descriptive statistics

\begin{tabular}{|c|c|c|c|c|c|c|}
\hline \multirow[b]{2}{*}{ Variables } & \multicolumn{2}{|c|}{ First wave } & \multicolumn{2}{|c|}{ Last wave } & \multicolumn{2}{|c|}{ All waves } \\
\hline & Mean & SD & Mean & SD & Mean & SD \\
\hline \multicolumn{7}{|l|}{ Health outcomes: } \\
\hline Subjective health & 2.50 & 0.87 & 2.36 & 0.87 & 2.41 & 0.86 \\
\hline Physical health & 6.23 & 0.89 & 5.84 & 1.04 & 6.13 & 0.94 \\
\hline $\begin{array}{l}\text { High blood pressure/ } \\
\text { hypertension (\%) }\end{array}$ & 34.26 & & 49.09 & & 38.27 & \\
\hline Diabetes/high blood sugar (\%) & 14.42 & & 28.37 & & 19.20 & \\
\hline $\begin{array}{l}\text { Cancer or malignant tumour } \\
(\%)\end{array}$ & 1.76 & & 5.14 & & 2.55 & \\
\hline Chronic lung disease (\%) & 5.89 & & 7.56 & & 5.67 & \\
\hline Heart problems (\%) & 2.27 & & 6.11 & & 3.12 & \\
\hline Stroke (\%) & 1.48 & & 3.26 & & 1.76 & \\
\hline Arthritis/rheumatism (\%) & 16.37 & & 15.74 & & 15.40 & \\
\hline Psychological health & 5.44 & 2.33 & 5.32 & 2.55 & 5.33 & 2.43 \\
\hline \multicolumn{7}{|l|}{ Formal education: } \\
\hline Years of education & 6.51 & 4.78 & 6.50 & 4.71 & 6.46 & 4.75 \\
\hline \multicolumn{7}{|l|}{ Retirement timing: } \\
\hline Retirement status (\%) & - & - & 51.03 & 0.50 & 14.86 & 0.36 \\
\hline Current age & 57.90 & 6.45 & 68.27 & 5.69 & 61.54 & 7.66 \\
\hline \multicolumn{7}{|l|}{ Covariates: } \\
\hline $\begin{array}{l}\text { Income (in US } \$ 1,000 \text {, not } \\
\text { logged) }\end{array}$ & 11.28 & 83.32 & 7.24 & 50.26 & 9.53 & 64.98 \\
\hline Employed spouse (\%) & 46.29 & & 14.31 & & 30.94 & \\
\hline No spouse (\%) & 22.89 & & 31.58 & & 23.01 & \\
\hline Spouse not employed (\%) & 30.82 & & 54.11 & & 46.05 & \\
\hline Not in the labour force $(\%)$ & - & - & 27.60 & 0.45 & 19.42 & 0.40 \\
\hline Functional limitations index & 2.91 & 1.23 & 3.14 & 1.31 & 2.97 & 1.25 \\
\hline Psychological health & 5.43 & 2.33 & 5.31 & 2.55 & 5.33 & 2.43 \\
\hline Never smoked (\%) & 54.13 & 0.49 & 61.87 & 0.49 & 57.39 & 0.49 \\
\hline Ever smoked (\%) & 26.82 & 0.44 & 27.51 & 0.45 & 26.21 & 0.44 \\
\hline Current smoker (\%) & 19.05 & 0.39 & 12.47 & 0.33 & 16.40 & 0.37 \\
\hline Abstainer (\%) & 61.10 & 0.49 & 77.34 & 0.42 & 69.33 & 0.46 \\
\hline Light drinking behaviour (\%) & 31.13 & 0.46 & 18.03 & 0.38 & 24.07 & 0.43 \\
\hline $\begin{array}{l}\text { Moderate drinking behaviour } \\
(\%)\end{array}$ & 4.44 & 0.21 & 3.49 & 0.18 & 4.07 & 0.20 \\
\hline
\end{tabular}


Table 1. (Continued.)

\begin{tabular}{|c|c|c|c|c|c|c|}
\hline \multirow[b]{2}{*}{ Variables } & \multicolumn{2}{|c|}{ First wave } & \multicolumn{2}{|c|}{ Last wave } & \multicolumn{2}{|c|}{ All waves } \\
\hline & Mean & SD & Mean & SD & Mean & SD \\
\hline Heavy drinking behaviour (\%) & 3.32 & 0.18 & 1.14 & 0.11 & 2.54 & 0.16 \\
\hline Women (\%) & 53.57 & & 55.86 & & 54.15 & \\
\hline Indigenous ethnicity (\%) & 4.82 & & 5.13 & & 4.85 & \\
\hline Professional worker (\%) & 16.50 & & 16.29 & & 16.44 & \\
\hline $\begin{array}{l}\text { Clerical/sale/service worker } \\
(\%)\end{array}$ & 34.10 & & 33.9 & & 34.88 & \\
\hline Blue-collar worker (\%) & 49.40 & & 49.81 & & 48.68 & \\
\hline $\mathrm{N}$ & \multicolumn{2}{|c|}{2,430} & \multicolumn{2}{|c|}{1,834} & \multicolumn{2}{|c|}{6,276} \\
\hline
\end{tabular}

Notes: Raw values before transformations are reported for all variables, unless explicitly noted. Percentages are reported for all dichotomous variables. SD: standard deviation.

Figure 3 shows that having any formal education fully compensates for the detrimental association between earlier retirement and subjective health. The left panel shows that retiring too early is detrimental for the subjective health of individuals without formal education, but at age 66.26 individuals that retired and those that remained in the labour force have the same point estimate in subjective health, suggesting that continued employment into older ages has no significant association with subjective health. The right panel suggests that retirement timing is not significantly associated with the subjective health of individuals with formal education.

Figure 4 displays analogous information for physical health. Similarly, a retirement that happens too early is associated with worse health among individuals with no education, but at age 68.1 individuals that retired and those that remained in the labour force have the same point estimate in health, suggesting that continued employment into older ages has no significant association with physical health (left panel). Also consistent with results on subjective health, there is no association between retirement timing and physical health among individuals with formal education (right panel).

Overall, these results are consistent with previous literature suggesting that formal education is associated with better late-life health, as well as supporting our hypotheses that formal education buffers the negative (subjective and physical) health consequences of early transitions into retirement. The hypothesis that the moderating effect of education is stronger for subjective than physical health was inconclusive, as it was only supported when using random-effects models, but not when using fixed-effects models.

\section{Discussion}

This study tested the protective effect of formal education on the health consequences of early transitions into retirement. In order to assess the full power of education, we used a representative sample of older adults in Mexico, a middle-income 
Table 2. Panel regression results for the average effects on health

\begin{tabular}{|c|c|c|c|c|c|c|}
\hline \multirow[b]{2}{*}{ Variables } & \multicolumn{3}{|c|}{ Subjective health } & \multicolumn{3}{|c|}{ Physical health } \\
\hline & Coeff. & SD & $p$ & Coeff. & SD & $p$ \\
\hline \multicolumn{7}{|l|}{ Retirement timing: } \\
\hline Retirement status & -0.39 & 0.18 & 0.030 & -0.45 & 0.19 & 0.016 \\
\hline Age & -0.06 & 0.06 & 0.337 & -0.26 & 0.06 & 0.000 \\
\hline Age squared & 0.04 & 0.03 & 0.205 & -0.01 & 0.04 & 0.779 \\
\hline \multicolumn{7}{|l|}{ Interactions: } \\
\hline Retirement $\times$ Age & 0.59 & 0.29 & 0.039 & 0.62 & 0.33 & 0.060 \\
\hline Retirement $\times$ Age squared & -0.20 & 0.11 & 0.059 & -0.19 & 0.13 & 0.133 \\
\hline Retirement $\times$ Years of education & 0.04 & 0.02 & 0.050 & 0.05 & 0.02 & 0.009 \\
\hline $\begin{array}{l}\text { Retirement } \times \text { Years of } \\
\text { education } \times \text { Age }\end{array}$ & -0.06 & 0.04 & 0.146 & -0.10 & 0.04 & 0.014 \\
\hline $\begin{array}{l}\text { Retirement } \times \text { Years of } \\
\text { education } \times \text { Age squared }\end{array}$ & 0.02 & 0.02 & 0.454 & 0.04 & 0.02 & 0.018 \\
\hline Age $\times$ Years of education & 0.00 & 0.01 & 0.947 & -0.01 & 0.01 & 0.355 \\
\hline Age squared $\times$ Years of education & 0.00 & 0.01 & 0.896 & 0.00 & 0.01 & 0.991 \\
\hline \multicolumn{7}{|l|}{ Covariates: } \\
\hline Income (in US $\$ 1,000$, logged) & 0.12 & 0.07 & 0.064 & 0.07 & 0.07 & 0.292 \\
\hline No spouse & 0.04 & 0.07 & 0.579 & -0.26 & 0.07 & 0.000 \\
\hline Spouse not employed & -0.06 & 0.03 & 0.045 & 0.05 & 0.03 & 0.087 \\
\hline Not in the labour force & -0.06 & 0.03 & 0.068 & -0.05 & 0.04 & 0.143 \\
\hline Functional limitations index & -0.04 & 0.01 & 0.000 & -0.01 & 0.01 & 0.385 \\
\hline Psychological health & 0.07 & 0.01 & 0.000 & 0.05 & 0.01 & 0.000 \\
\hline Ever smoked & 0.00 & 0.03 & 0.889 & 0.04 & 0.04 & 0.265 \\
\hline Current smoker & 0.08 & 0.05 & 0.096 & 0.22 & 0.06 & 0.000 \\
\hline Light drinking behaviour & 0.09 & 0.03 & 0.004 & 0.04 & 0.03 & 0.219 \\
\hline Moderate drinking behaviour & -0.05 & 0.07 & 0.446 & 0.10 & 0.06 & 0.106 \\
\hline Heavy drinking behaviour & 0.17 & 0.08 & 0.034 & 0.19 & 0.09 & 0.043 \\
\hline Constant & 1.99 & 0.07 & 0.000 & 5.99 & 0.08 & 0.000 \\
\hline
\end{tabular}

Notes: $\mathrm{N}$ (individuals) $=2,430 ; \mathrm{N}$ (observations) $=6,276$. Reference categories for categorical variables are employed spouse and professional/managerial worker. Continuous variables are mean-centred. Coeff.: coefficient. SD: standard deviation.

country that is characterised by a wider variation in years of education in the population than in most high-income countries. We found, as others before, that there was a beneficial effect of formal education on later-life health (Lleras-Muney, 2005; Luo and Waite, 2005; Majer et al., 2011; Mäki et al., 2014; Vogl, 2014). Due to the wide spread of years of education in our sample, however, we were for the first time 
No formal education
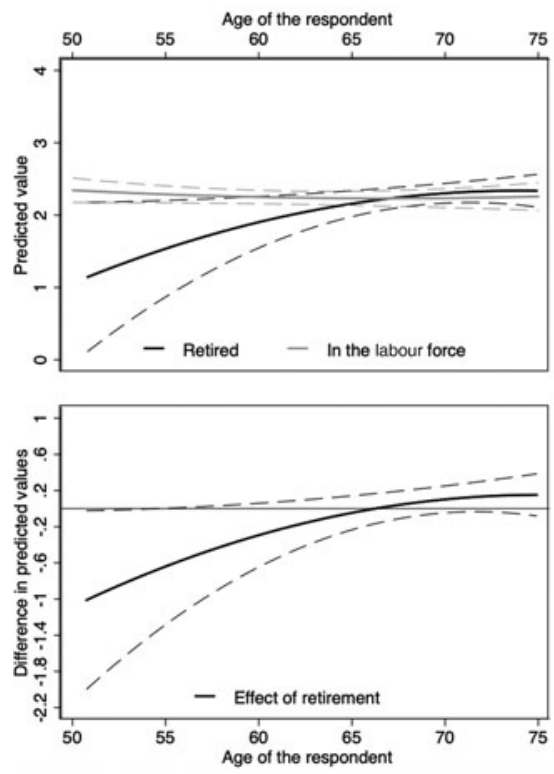

Formal education
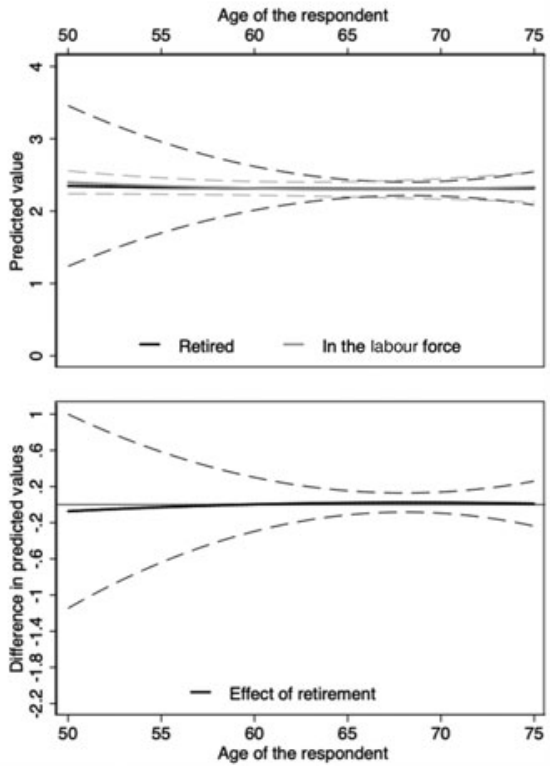

Figure 3. Subjective health effects of retirement timing for individuals with and without formal education. Note: Dashed lines show the 95 per cent confidence intervals.

No formal education
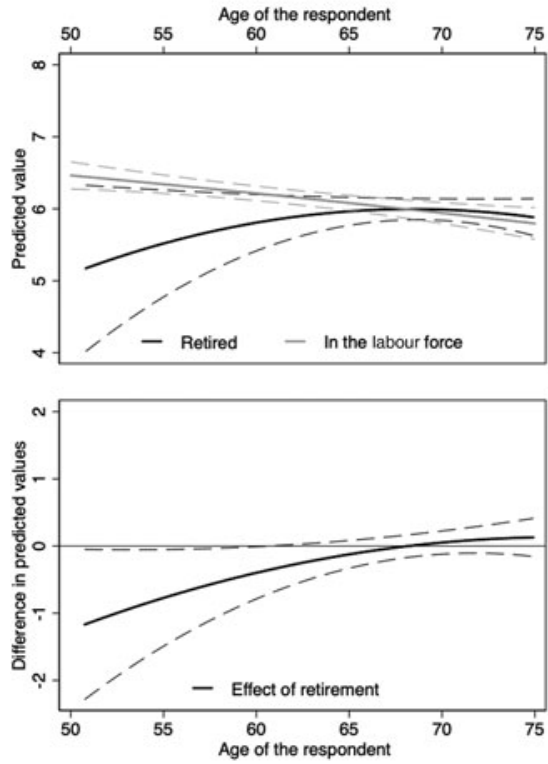

Formal education
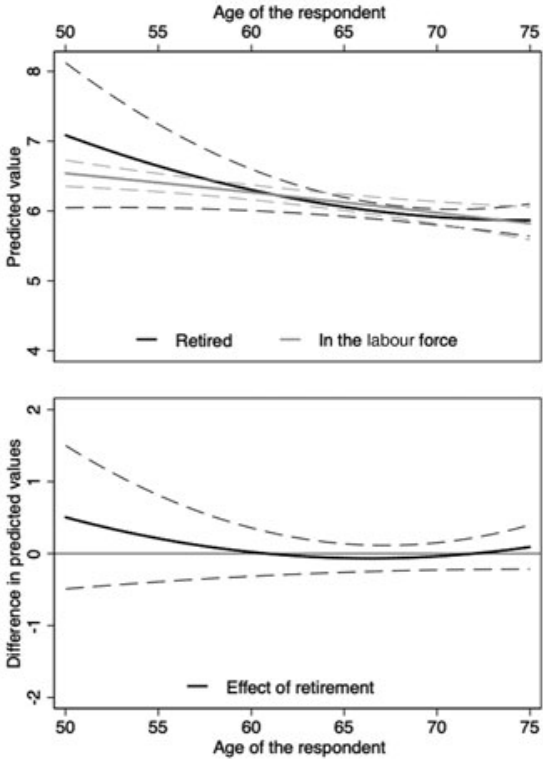

Figure 4. Physical health effects of retirement timing for individuals with and without formal education. Note: Dashed lines show the 95 per cent confidence intervals. 
able to find a strong buffering effect of formal education on this association between early transitions into retirement and worse health. This moderating role of education on the association between retirement and health is stronger and more consistent than what has been previously observed in one study for education (Hessel, 2016) and in multiple studies for occupation as a marker of SES (Mein et al., 2003; Nooyens et al., 2005; Neuman, 2006; Chandola et al., 2007; Chung et al., 2009; Zins et al., 2011; Coe et al., 2012). The latter finding is consistent with the fact that socio-economic differences in health based on occupation seem to decrease after retirement more than socio-economic differences based on education (Marmot and Shipley, 1996).

We did not find strong evidence suggesting that the moderating effect of education varied by health outcome. Prior evidence documented that subjective outcomes are more sensitive to socio-economic exposures (Franks et al., 2003; Maas et al., 2006; Stewart et al., 2019; Borgonovi and Pokropek, 2016; Hessel, 2016), while physical health outcomes involve more complex and longer pathways for SES-related exposures to 'get under the skin' (Ferraro and Shippee, 2009; Miller et al., 2009; Hertzman and Boyce, 2010; Phelan et al., 2010; Matthews and Gallo, 2011). Based on our results we conclude, however, that the association between early transition into retirement and worse health is fully buffered by education for both subjective and physical health.

Potential mechanisms that may explain the moderating effect of formal education include the differentials between higher- and lower-educated individuals in terms of cognitive and non-cognitive skills, lifestyles, financial and informational resources, quantity and quality of activities, social connections and environmental exposures (Cutler and Lleras-Muney, 2010; Stenholm et al., 2014; Van Rijn et al., 2014; Vogl, 2014; Fisher et al., 2016; Staudinger et al., 2016). In exploratory follow-up analyses (available upon request), we found that this protective effect of education stems partly from the higher concentration of resources and the nature of post-retirement activities performed by individuals with more formal education relative to those with less formal or without education. Individuals with formal education accumulate wealth and resources (Kawachi et al., 2010), allowing them to cope better with the transition into retirement. Consistent with previous literature, we found that by controlling for financial resources, individuals with more education seem to allocate their available resources in a more efficient way in terms of the production or protection of their health by engaging in a greater variety and higher quality of post-retirement activities (Grossman, 2006; Oreopoulos and Salvanes, 2011). These results are novel in highlighting a previously overlooked dimension of the non-pecuniary benefits of formal education by demonstrating that basic formal education during childhood and adolescence is associated with better health roughly half a century later, when they are older adults and transitioning into retirement. More research is needed, however, to understand the causal pathways connecting retirement timing and health, and the mechanisms that explain the moderating effect of formal education.

These findings have policy and practical implications for low- and middle-income countries facing a rapidly ageing population without universal schooling. Mexico and other countries where schooling is not universal, such as China and India (United Nations, 2013), would benefit from considering formal 
education as a potential long-term intervention to improve the health of older adults and protect them from potential negative effects of transitions into retirement that happen too early. Our results highlight that policies and interventions promoting healthy ageing should consider formal education as an integral antecedent of later-life health and also a potential tool to address socio-economic disparities in health among lower- and middle-income countries (Borgonovi and Pokropek, 2016). They also suggest that individuals with little or no formal education need more support during their transition into retirement in order to experience similar health outcomes as individuals with formal education.

Despite these important findings, this research has some limitations that we would like to acknowledge. The main limitations are that both health outcomes are self-reported and that at the time of the analyses there were only three waves of data available with an unusually uneven time lag between them. However, conducting this study in a middle-income country like Mexico, where numerous older adults have little or no formal education, allowed us to explore the protective effect of the most basic educational intervention; that is, formal education. Future research could explore differences in other health-related outcomes and the effects of retirement timing by other policy-relevant variables, such as job quality, partial retirement, pension adequacy and lifelong learning. Generating work environments that reinforce health, promoting partial retirements, improving the availability and generosity of old-age pensions, and promoting lifelong learning might constitute additional opportunities to improve health for older adults and to facilitate healthier transitions into retirement (Calvo, 2016; Staudinger et al., 2016; Azar et al., 2018; Calvo et al., 2018).

\section{Conclusion}

Extant literature documents that education is strongly associated with health throughout the lifecourse (e.g. Jamieson, 2007; Lutz and Samir, 2011; Majer et al., 2011; Vogl, 2014; Cutler et al., 2015) and that early transitions into retirement have average detrimental effects on health (e.g. Bonsang and Klein, 2012; Calvo et al., 2013; Fisher et al., 2016; Mazzonna and Peracchi, 2016). This study contributes to existing literature by documenting that formal education continues to be associated with health during the transition to retirement, and more specifically that formal education offsets the detrimental association between early transitions into retirement and both subjective and physical health. This novel evidence suggests that part of the non-pecuniary returns to interventions promoting formal education and literacy campaigns include improving health outcomes later in life, especially during the transition from work to retirement, a critical period for the health trajectories of older adults.

Supplementary material. The supplementary material for this article can be found at https://doi.org/10. $1017 /$ S0144686X19000928

Acknowledgements. The authors thank Michelle Castro, Alejandro Corvalán, Nicolás Garrido, Marco Morales, Natalia Sarkisian, Matías Tapia and two anonymous reviewers for their comments on previous versions of this article. Any remaining errors or inaccuracies are exclusively the responsibility of the authors. 
Author contributions. KA conducted data analyses, interpreted the findings and wrote the first draft of the manuscript. ASL supervised the analyses, interpreted the findings and edited the manuscript. UMS interpreted the findings, critically revised the argument and contributed to writing the manuscript. EC conceived the study, supervised the analyses, interpreted the findings and wrote the manuscript.

Financial support. This work was supported by Columbia University President's Global Innovation Fund and CONICYT/FONDECYT REGULAR/1140107.

Conflict of interest. The authors declare no conflicts of interest.

Ethical standards. Mexican Health and Aging Study (MHAS) data are publicly available to any registered user from the National Institutes of Health/National Institute on Aging in Mexico. The MHAS study protocol and instruments were approved by the Institutional Review Board or Ethics Committee of the University of Texas Medical Branch, the Instituto Nacional de Estadística y Geografía in Mexico and the Instituto Nacional de Salud Pública in Mexico.

\section{References}

Aguila E, Diaz C, Fu MM, Kapteyn A and Pierson A (2011) Living Longer in Mexico: Income Security and Health. Santa Monica, CA: RAND Corporation.

Azar A, Staudinger UM, Slachevsky A, Madero-Cabib I and Calvo E (2018) From snapshots to movies: the association between retirement sequences and aging trajectories in limitations to perform activities of daily living. Journal of Aging and Health 31, 293-321.

Ball K, Berch D, Helmers KF, Jobe JB, Leveck MD, Marsiske M, Unverzagt FW and Willis SL (2002) Effects of cognitive training interventions with older adults: a randomized controlled trial. Journal of the American Medical Association 288, 2271-2281.

Baltes P, Staudinger UM and Lindenberger U (2006) Lifespan theory in developmental psychology. In Lerner RM and Damon W (eds), Handbook of Child Psychology, 6th Edn. Hoboken, NJ: John Wiley and Sons, pp. 569-664.

Behncke S (2012) How does retirement trigger ill health? Health Economics 21, 282-300.

Bloom DE, Chatterji S, Kowal P, Lloyd-Sherlock P, McKee M, Rechel B, Rosenberg L and Smith JP (2015) Macroeconomic implications of population ageing and selected policy responses. The Lancet 385, 649-657.

Bonsang E, Adam S and Perelman S (2012) Does retirement affect cognitive functioning? Journal of Health Economics 31, 490-501.

Bonsang E and Klein TJ (2012) Retirement and subjective well-being. Journal of Economic Behavior \& Organization 83, 311-329.

Bonsang E and Van Soest A (2014) Satisfaction with daily activities after retirement in Europe. Ageing \& Society 35, 1146-1170.

Borgonovi F and Pokropek A (2016) Education and self-reported health: evidence from 23 countries on the role of years of schooling, cognitive skills and social capital. PLOS ONE 11, e0149716.

Calvo E (2016) Does the Chilean pension model influence life satisfaction? A multilevel longitudinal analysis. In Rojas M (ed.), Handbook of Happiness Research in Latin America. New York, NY: Springer, pp. 415-441.

Calvo E, Madero-Cabib I and Staudinger UM (2018) Retirement sequences of older Americans: moderately destandardized and highly stratified across gender, class, and race. The Gerontologist 58, 1166-1176.

Calvo E, Sarkisian N and Tamborini C (2013) Causal effects of retirement timing on subjective physical and emotional health. Journals of Gerontology 68, 73-84.

Chandola T, Ferrie J, Sacker A and Marmot M (2007) Social inequalities in self reported health in early old age: follow-up of prospective cohort study. British Medical Journal 334, 990-997.

Chung S, Domino ME, Stearns SC and Popkin BM (2009) Retirement and physical activity: analyses by occupation and wealth. American Journal of Preventive Medicine 36, 422-428.

Coe NB, von Gaudecker H-M, Lindeboom M and Maurer J (2012) The effect of retirement on cognitive functioning. Health Economics 21, 913-927.

Currie J and Moretti E (2007) Biology as destiny? Short- and long-run determinants of intergenerational transmission of birth weight. Journal of Labor Economics 25, 231-263. 
Cutler D, Huang W and Lleras-Muney A (2015) When does education matter? The protective effect of education for cohorts graduating in bad times. Social Science \& Medicine 127, 63-73.

Cutler D and Lleras-Muney A (2008) Education and health: evaluating theories and evidence. In House J, Schoeni R, Kaplan G and Pollack H (eds), Making Americans Healthier: Social and Economic Policy as Health Policy. New York, NY: Russell Sage Foundation, pp. 29-60.

Cutler D and Lleras-Muney A (2010) Understanding differences in health behaviors by education. Journal of Health Economics 29, 1-28.

Dehejia RH and Wahba S (2002) Propensity score-matching methods for nonexperimental causal studies. Review of Economics and Statistics 84, 151-161.

Dhaval D, Rashad R and Spasojevic J (2008) The effects of retirement on physical and mental health outcomes. Southern Economic Journal 75, 497-523.

Ferraro KF and Shippee TP (2009) Aging and cumulative inequality: how does inequality get under the skin? The Gerontologist 49, 333-343.

Fisher G, Chaffee D and Sonnega A (2016) Retirement timing: a review and recommendations for future research. Work, Aging and Retirement 2, 230-261.

Fisher G, Stachowski A, Infurna FJ, Faul JD, Grosch J and Tetrick LE (2014) Mental work demands, retirement, and longitudinal trajectories of cognitive functioning. Journal of Occupational Health Psychology 19, 231-242.

Franks P, Gold M and Fiscella K (2003) Sociodemographics, self-rated health, and mortality in the US. Social Science \& Medicine 56, 2505-2514.

Freedman D and Berk R (2008) Weighting regressions by propensity scores. Evaluation Review 32, 392409.

Grossman M (2006) Education and nonmarket outcomes. In Hanushek E and Welch F (eds), Handbook of the Economics of Education, Vol. 1. Amsterdam: Elsevier, pp. 577-633.

Hertzman C and Boyce T (2010) How experience gets under the skin to create gradients in developmental health. Annual Review of Public Health 31, 329-347.

Hessel P (2016) Does retirement (really) lead to worse health among European men and women across all educational levels? Social Science \& Medicine 151, 19-26.

Hirano K and Imbens G (2001) Estimation of causal effects using propensity score weighting: an application to data on right heart catheterization. Health Services and Outcomes Research Methodology 2, 259278.

Imai K and Kim IS (2019) When should we use unit fixed effects regression models for causal inference with longitudinal data? American Journal of Political Science 63, 467-490.

Instituto Nacional de Estadística y Geografía (2012) Sample Design of the Mexican Health and Aging Study (MHAS). Available at http://mhasweb.org.

Iparraguirre J (2014) Physical functioning in work and retirement: commentary on age-related trajectories of physical functioning in work and retirement - the role of sociodemographic factors, lifestyle and disease by Stenholm et al. Journal of Epidemiology and Community Health 86, 493-499.

Jamieson A (2007) Higher education study in later life: what is the point? Ageing \& Society 27, 363-384.

Kajitani S, Sakata KEI and McKenzie C (2016) Occupation, retirement and cognitive functioning. Ageing \& Society 37, 1568-1596.

Kaufman L and Rousseeuw P (2009) Finding Groups in Data: An Introduction to Cluster Analysis. New York, NY: John Wiley \& Sons.

Kawachi I, Adler N and Dow W (2010) Money, schooling, and health: mechanisms and causal evidence. Annals of the New York Academy of Sciences 1186, 56-68.

Kuhntopf S and Tivig T (2012) Early retirement and mortality in Germany. European Journal of Epidemiology 27, 85-89.

Lleras-Muney A (2005) The relationship between education and adult mortality in the United States. Review of Economic Studies 72, 189-221.

Luo Y and Waite LJ (2005) The impact of childhood and adult SES on physical, mental, and cognitive well-being in later life. Journals of Gerontology 60, S93-S101.

Lutz W, Butz WP and Samir KC (eds) (2014) World Population and Human Capital in the Twenty-first Century. Oxford: Oxford University Press.

Lutz W and Samir K (2011) Global human capital: integrating education and population. Science 333, 587-592. 
Maas J, Verheij R, Groenewegen P, De Vries S and Spreeuwenberg P (2006) Green space, urbanity, and health: how strong is the relation? Journal of Epidemiology and Community Health 60, 587-592.

Majer IM, Nusselder WJ, Mackenbach JP and Kunst AE (2011) Socioeconomic inequalities in life and health expectancies around official retirement age in 10 Western-European countries. Journal of Epidemiology and Community Health 65, 972-979.

Mäki NE, Martikainen PT, Eikemo T, Menvielle G, Lundberg O, Östergren O and Mackenbach JP (2014) The potential for reducing differences in life expectancy between educational groups in five European countries: the effects of obesity, physical inactivity and smoking. Journal of Epidemiology and Community Health 68, 635-640.

Marmot MG and Shipley MJ (1996) Do socioeconomic differences in mortality persist after retirement? 25 year follow up of civil servants from the first Whitehall study. British Medical Journal 313, 11771180.

Matthews KA and Gallo LC (2011) Psychological perspectives on pathways linking socioeconomic status and physical health. Annual Review of Psychology 62, 501-530.

Mazzonna F and Peracchi F (2016) Unhealthy retirement? Journal of Human Resources 52, 128-151.

Mein G, Martikainen P, Hemingway H, Stansfeld S and Marmot M (2003) Is retirement good or bad for mental and physical health functioning? Whitehall II longitudinal study of civil servants. Journal of Epidemiology and Community Health 51, 46-49.

Miller G, Chen E and Cole SW (2009) Health psychology: developing biologically plausible models linking the social world and physical health. Annual Review of Psychology 60, 501-524.

Morrow-Howell N, Hinterlong J and Sherraden M (2001) Productive Aging: Concepts and Challenges. Baltimore, MD: Johns Hopkins University Press.

Murill S and Venegas F (2011) Coverage of the retirement system and factors associated to the access to a retirement pension in Mexico. Papeles de la Población 17, 209-250.

Narushima M, Liu J and Diestelkamp N (2018) Lifelong learning in active ageing discourse: its conserving effect on wellbeing, health and vulnerability. Ageing \& Society 38, 651-675.

Neuman K (2006) Will retiring from this job kill me? The health effect of retirement in different industries and occupations. In Proceedings of the Midwest Business Administration Association Conference, Chicago, IL, pp. 56-65.

Nooyens AC, Visscher TL, Schuit AJ, van Rossum CT, Verschuren WM, van Mechelen W and Seidell JC (2005) Effects of retirement on lifestyle in relation to changes in weight and waist circumference in Dutch men: a prospective study. Public Health Nutrition 8, 1266-1274.

Oreopoulos P and Salvanes KG (2011) Priceless: the non-pecuniary benefits of schooling. Journal of Economic Perspectives 25, 159-184.

Palloni A, Pinto-Aguirre G and Pelaez M (2002) Demographic and health conditions of ageing in Latin America and the Caribbean. International Journal of Epidemiology 31, 762-771.

Phelan JC, Link BG and Tehranifar P (2010) Social conditions as fundamental causes of health inequalities: theory, evidence, and policy implications. Journal of Health and Social Behavior 51, S28-S40.

Rehkopf D, Adler N and Rowe J (2017) The impact of health and education on future labour force participation among individuals aged 55-74 in the United States of America: the MacArthur Foundation Research Network on an Aging Society. Ageing \& Society 37, 1313-1337.

Rosenbaum P and Rubin D (1983) The central role of the propensity score in observational studies for causal effects. Biometrika 70, 41-55.

Ross CE and Mirowsky J (1999) Refining the association between education and health: the effects of quantity, credential, and selectivity. Demography 36, 445-460.

Rowe JW (2015) Successful aging of societies. Daedalus 144, 5-12.

Rubin D (1997) Estimating causal effects from large data sets using propensity scores. Annals of Internal Medicine 127, 757-763.

Scharn M, Sewdas R, Boot CR, Huisman M, Lindeboom M and van der Beek AJ (2018) Domains and determinants of retirement timing: a systematic review of longitudinal studies. BMC Public Health 18, 1083.

Siegrist J, Wahrendorf M, Von Dem Knesebeck O, Jürges H and Börsch-Supan A (2007) Quality of work, well-being, and intended early retirement of older employees-baseline results from the SHARE Study. European Journal of Public Health 17, 62-68.

Staudinger UM (2015) The future of aging: how I will live. In Barysch K (ed.), Our World and Us: How Our Environment and Our Societies Will Change. Munich, Germany: Allianz SE, pp. 137-149. 
Staudinger UM, Finkelstein R, Calvo E and Sivaramakrishnan K (2016) A global view on the effects of work on health in later life. The Gerontologist 56, 281-292.

Staudinger UM and Kocka J (2010) More Years, More Life. Recommendations of the Joint Academy Initiative on Aging. Halle (Saale), Germany: Deutsche Akademie der Naturforscher LeopoldinaNationale Akademie der Wissenschaften. (In German)

Stenholm S, Westerlund H, Salo P, Hyde M, Pentti J, Head J, Kivimäki M and Vahtera J (2014) Age-related trajectories of physical functioning in work and retirement: the role of sociodemographic factors, lifestyle and disease. Journal of Epidemiology and Community Health 68, 503-509.

Stewart J, Auais M, Bélanger E and Phillips S (2019) Comparison of self-rated and objective successful ageing in an international cohort. Ageing \& Society 39, 1317-1334.

United Nations (2013) Human Development Report. New York, NY: UN Development Programme.

United Nations (2015) World Population Prospects: The (2015) Revision. New York, NY: UN Population Division.

Van der Heide I, Van Rijn RM, Robroek SJ, Burdorf A and Proper KI (2013) Is retirement good for your health? A systematic review of longitudinal studies. BMC Public Health 13, 1-11.

Van der Noordt M, IJzelenberg H, Droomers M and Proper KI (2014) Health effects of employment: a systematic review of prospective studies. Occupation and Environmental Medicine 71, 730-736.

Van Dijk KR, Van Gerven PW, Van Boxtel MP, Van der Elst W and Jolles J (2008) No protective effects of education during normal cognitive aging: results from the 6-year follow-up of the Maastricht Aging Study. Psychology and Aging 23, 119-130.

Van Rijn RM, Robroek SJ, Brouwer S and Burdorf A (2014) Influence of poor health on exit from paid employment: a systematic review. Occupation and Environmental Medicine 71, 295-301.

Vogl TS (2014) Education and health in developing economies. In Cuyler AJ (ed.), Encyclopedia of Health Economics. Waltham, MA: Elsevier, pp. 246-249.

Wong R, Michaels-Obregon A and Palloni A (2015) Cohort profile: the Mexican Health and Aging Study (MHAS). International Journal of Epidemiology 263, 1-10.

Wong R and Palloni A (2009) Aging in Mexico and Latin America. In Uhlenberg P (ed.), International Handbook of Population Aging. New York, NY: Springer, pp. 231-252.

Zins M, Gueguen A, Kivimaki M, Singh-Manoux A, Leclerc A, Vahtera J, Westerlund H, Ferrie JE and Goldberg M (2011) Effect of retirement on alcohol consumption: longitudinal evidence from the French Gazel cohort study. PLOS ONE 6, e26531.

Cite this article: Allel K, León AS, Staudinger UM, Calvo E (2021). Healthy retirement begins at school: educational differences in the health outcomes of early transitions into retirement. Ageing \& Society 41, 137-157. https://doi.org/10.1017/S0144686X19000928 